\title{
Correction to: The Impact of Digitalization and Sustainable Development Goals in SMEs' Strategy: A Multi-Country European Study
}

\author{
Zhanna Belyaeva and Yana Lopatkova
}

\section{Correction to:}

Chapter 2 in: A. Thrassou et al. (eds.), The Changing Role of SMEs in Global Business, Palgrave Studies in Cross-disciplinary Business Research, In Association with EuroMed Academy of Business, https://doi.org/10.1007/978-3-030-45835-5_2

The original version of this chapter was revised as the order of chapter authors' first and last names was inadvertently transposed and published. The first names of the authors are corrected to Zhanna and Yana instead of last name Belyaeva and Lopatkova.

The updated version of the chapter can be found at https://doi.org/10.1007/978-3-030-45835-5_2

(C) The Author(s), under exclusive license to Springer Nature Switzerland AG 2021 